\title{
Accuracy study on "Osteorisk": a new osteoporosis screening clinical tool for women over 50 years old
}

\author{
Department of Gynecology and Obstetrics, Faculdade de Medicina do \\ ABC, São Bernardo do Campo, São Paulo, Brazil
}

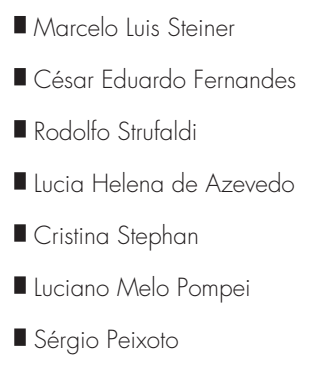

\section{INTRDDUCTION}

Osteoporosis is a syndrome characterized by low bone mass and deterioration of the bone microarchitecture, which results in greater fragility of the skeleton and increased risk of fractures. ${ }^{1}$ It is the most common bone metabolism disease, affecting around 200 million people around the world, and it is the greatest cause of diminished quality of life, morbidity and mortality among postmenopausal women. ${ }^{1-3}$

Estrogen deficiency is responsible for 30 to $50 \%$ of the bone loss observed during women's lives. ${ }^{3}$ In Brazil, it has been estimated that 10 million individuals are affected by osteoporosis ${ }^{4}$ and that, because of the greater ages attained by the population, the number of hip fractures among men and women between 50 and 60 years old will increase by $400 \%$ by 2050 , in comparison with the prevalence in $1950 .{ }^{4}$ This signifies a major public health problem with enormous financial cost relating to caring for this morbid condition..$^{5-10}$ It has become important to achieve early identification of individuals at greater risk of this disease, in order to implement preventive measures. ${ }^{5-10}$

Osteoporosis diagnoses are made from bone mineral density (BMD) measurements. BMD measurements by means of dual X-ray absorptiometry (DXA), also known as bone densitometry, are considered to be the gold standard test for diagnosing this disease. ${ }^{8}$ Such measurements provide high precision in evaluating the mineral density of the axial skeleton and enable precise decisions in relation to the treatment and follow-up for the disease. However, DXA is not widely available within public healthcare, thereby making evaluations on all postmenopausal women logistically impossible and prohibitively expensive. ${ }^{2,8,11-14}$

To minimize such difficulties, new methods for measuring BMD have been developed and made available on the market.
These methods include peripheral DXA for forearm and heel measurements, peripheral quantitative computed tomography (QCT) for wrist and tibia studies, radiographic absorptiometry for fingers, and quantitative ultrasound or ultrasonometry (QUS) for heels and other areas. ${ }^{15}$

The availability of technology for evaluating bone mass by using peripheral sites in the skeleton has improved test accessibility because the technology is portable, faster, easier to perform and less costly. And most importantly, these methods can be used for calculating fracture risks both in peripheral and in central sites, with similar performance to central BMD measurements, except for calculations on the risk of hip fractures, which may be more precise with bone densitometry of the hip bone. The BMD of the peripheral skeleton, including the distal radius, phalanx and heel, correlates reasonably well with the density of the axial skeleton (hip and spinal column). ${ }^{8,12}$

To have all postmenopausal women undergo these examinations with the aim of screening them for osteoporosis is impossible and not recommendable, considering that many women do not present any risk of osteoporosis and will not develop the disease. ${ }^{5,11,13}$ On the other hand, Siris et al. ${ }^{8}$ studied 200,160 American women over the age of 50 years who had undergone different peripheral BMD measurement methods and found that half of them did not know that they presented decreased BMD, while $7 \%$ presented osteoporosis. This finding is very important, because individuals diagnosed with osteoporosis have 2.74 times greater chance of presenting bone fractures within one year, and those with osteopenia have 1.73 times greater chance. ${ }^{6,8,9}$

The ideal would be to have clinical methods capable of identifying patients who are at greater risk of osteoporosis. These methods

\section{ABSTRACT}

CONTEXT AND OBJECTIVE: Osteoporosis is the greatest cause of quality-of-life reductions, morbidity and mortality among postmenopausal women, with growing incidence as populations age. Clinical tools like Osteorisk provide an easyaccess and low-cost alternative method that helps physicians to reduce the need for dual-energy X-ray absorptiometry (DXA), the expensive gold standard examination for diagnosing osteoporosis. The aim here was to study the accuracy of Osteorisk using heel ultrasonography for bone mineral density (BMD).

DESIGN AND SETTING: Cross-sectional study, at Faculdade de Medicina do ABC.

METHODS: A structured questionnaire was applied to 615 postmenopausal women, with anthropometric measurements, Osteorisk calculations and quantitative ultrasound on the heel using Sonost 2000 equipment.

RESULTS: 461 women were included, with mean age $60 \pm 9$ years, weight $67.6 \pm 12.9 \mathrm{~kg}$ and body mass index (BMI) $28.8 \pm 5.0 \mathrm{~kg} / \mathrm{m}^{2}$. Their Osteorisk classifications were: $61.0 \%$ lowrisk, $28.4 \%$ medium-risk and $10.6 \%$ high-risk. Quantitative ultrasound showed $81.3 \%$ low-risk, $10.0 \%$ medium-risk and $8.7 \%$ high-risk regarding osteoporosis. Statistically significant results were observed ( $p<0.001)$ when Osteorisk was correlated with age, years since menopause and BMI. Correlating these same variables with quantitative ultrasound, statistically significant results were observed for age $(p<0.001)$, years since menopause $(p<0.001)$ and $B M$ $(p<0.006)$. The sensitivity, specificity, negative predictive value and positive predictive value for Osteorisk were $64 \%, 6.7 \%, 89 \%$ and $30.6 \%$, respectively.

CONCLUSION: Osteorisk is a valid tool for screening for women at low risk of osteoporosis, making it possible for these women not to have to undergo densitometry.

KEY WORDS: Osteoporosis. Bone mineral density. Screening. Ultrasonography. Risk factors. 
have still not been defined, since the guidelines are insufficiently precise for selecting such women. ${ }^{5}$ One alternative would be to establish a way of evaluating clinical risk factors that would identify women with greater likelihood of benefiting from such examinations. If these evaluations correctly differentiated the women who presented bone mass loss or osteoporosis from those with normal densitometry results, the need for bone densitometry examinations could be reduced. ${ }^{11-13,16}$

In the recent literature, there is a proven method for identifying osteoporosis risks that is easy to use and has low cost, called the "Osteorisk" risk assessment tool. ${ }^{17}$ Osteorisk has been validated in Asia, Europe, the United States and Latin America, undergoing adjustments in accordance with each population studied. ${ }^{4}$ According to Sen et al., the sensitivity of this method reaches $94 \%$ and the specificity, $45 \% .{ }^{4}$ Osteorisk is based on a series of statistical calculations and, using age and body weight variables allocated in a defined table, it allows the risk of osteoporosis to be classified as high, moderate or low. On the basis of these results, doctors can identify patients who are at greater risk of low bone mass and request examinations of higher complexity, and even begin therapy if it is impossible to undertake such examinations. ${ }^{4,5,11-13}$

The aim of Osteorisk is not to diagnose osteoporosis or osteopenia, but to identify women with a greater likelihood of developing low BMD, so that they can be advised to undergo bone densitometry examination. In this manner, the effectiveness of detecting patients with osteoporosis and osteopenia is increased and the wastage of unnecessary examinations is avoided. ${ }^{4,5,11-13,16}$

\section{口BJECTIVE}

In the present study, the objective was to compare BMD measurements obtained by means of quantitative ultrasound on the heel and by means of the Osteorisk method, among a population of postmenopausal women. Our aim was to confirm the applicability of the Osteorisk index to our population, and thus to use it in daily medical practice within our service.

METHDDS

\section{LOCATION AND}

PRPULATION GTUDIED

This study was granted prior approval by the Research Ethics Committee of Faculdade de Medicina do ABC, and was conducted in the municipality of São Bernardo do Campo, in the Greater São Paulo region, which is in southeastern Brazil. São Bernardo do Campo is a predominantly urban municipality with a population of approximately 700,000 inhabitants. ${ }^{18}$ The study was carried out between September and November 2005.

\section{INCLUBION AND}

\section{EXCLUBION CRITERIA}

For inclusion in the study, the women had to be over 50 years old and had to have been postmenopausal for at least six months, with or without climacteric symptoms. They had to have had no utilization within the last six months of medications such as estrogen, progestogen, androgen, aromatase inhibitor, bisphosphonates, calcium, corticoids, estrogen modulators, parathormone, fluorine, anticonvulsants or lithium, or high doses of antacids.

Women aged less than 50 years were excluded, as were those who presented severe bone pains, bone implants or histories of fractures, bone metabolism dysfunction, bone metastases, thyroid abnormalities or liver diseases.

\section{NTERVIEW}

The patients were called in to undergo ultrasonometry on the heel by invitation issued by community health agents working for the city authorities of São Bernardo do Campo. A structured questionnaire was applied to the individuals who took up the invitation, and it was filled out on their behalf by doctors or medical students. Anthropometric measurements were also made. All the participants were given explanations regarding the examination, and they signed a statement of free and informed consent. By the end of this recruitment period, 615 patients had been interviewed in the study, but 461 women were included in this study.

Detailed descriptions were obtained of any previous diseases among these patients, such as thyroid abnormalities, parathyroid abnormalities, diabetes mellitus, systemic arterial hypertension, rheumatoid arthritis, liver disease and intestinal malabsorption syndromes (neoplasias or gastrointestinal surgery causing reduced absorption). Likewise, details were obtained regarding previous or present use of corticosteroids, thyroid hormones and hormonal therapy.

Information was collected from each individual regarding personal or family histories of bone fractures and osteoporosis, socioeconomic level, habits such as smoking and alcohol use, profession, schooling level and physical activity. The interview also included obtaining informa- tion regarding age, menarche, menopause and obstetric and surgical histories.

\section{ANTHROPRMETRIC \\ MEABUREMENTS}

Weight and height were measured using an anthropometric balance, with the patients in orthostatic position, wearing light clothes and without shoes. The body mass index was calculated by means of dividing the weight in kilograms by the square of the height in meters.

\section{DBTERRIGK}

Osteorisk is an index developed by Sen et al. ${ }^{4}$ to categorize the risk of osteoporosis as low, medium or high. It was constructed from a study carried out in six centers in Latin America. After multivariate regression analysis of eight osteoporosis risk factors, a model using only age and body weight was obtained. Based on this model, Osteorisk is calculated as $0.2 \times$ [(body weight in $\mathrm{kg}$ ) - (age in years)]. In the low-risk category, the Osteorisk index is greater than 1, while in the high-risk category it is less than -2 and in the medium-risk category it is greater than -2 and less than 1 . The results are represented graphically to simplify their clinical use (not shown). ${ }^{4}$

\section{MEABUREMENT OF BONE MABg}

Bone mass was measured from the sound velocity (meters per second), by means of ultrasonometry on the heel, using the Sonost 2000 equipment (United States, 2000). This portable apparatus uses gel as the conduction medium and is capable of measuring sound velocities in bones.

The measurement was done on the right heel for all patients. The examinations were performed by a single trained professional. The apparatus was calibrated daily.

The T-score for each individual was calculated using the peak value for sound velocities for a given population of young adults, with standard deviation, by means of the following equation: ${ }^{19}$ T-score $=$ sound velocity (individual) - sound velocity (peak value for young adults)/standard deviation (peak value for young adults). The peak value for the sound velocities for young adults were calculated from an estimated peak bone mass, which was defined as the mean for the maximum bone mass attained by young healthy adults, matched for race and sex. The individual under examination was classified in the following manner:

Low risk: T-score higher than -1.5 .

Medium risk: T-score between -1.5 and -1.99 .

High risk: T-score lower than -2.0 . 
To evaluate the sensitivity, specificity, positive predictive value (PPV) and negative predictive value (NPV), the medium and high-risk results were grouped and considered together.

\section{BTATIBTICAL ANALYGIE}

The data were summarized as means \pm standard deviations in the case of quantitative variables, and as numbers and percentages for qualitative variables.

The concordance between the ultrasonometry and Osteorisk results was evaluated by means of calculating Kappa statistics accompanied by their respective $95 \%$ confidence intervals $(95 \% \mathrm{CI})$.

The chi-squared test was utilized for evaluating associations between qualitative variables, and analysis of variance (ANOVA) for comparing the means of quantitative variables according to the Osteorisk or ultrasonometry categories. The Brown-Forsythe correction was used in cases in which the equality of variance test was rejected. ${ }^{20}$

For all the statistical analyses, a significance level of 5\% ( $\alpha=0.05)$ was adopted. In other words, results that presented $\mathrm{p}$-values less than $0.05(\mathrm{p}<0.05)$ were considered to be significant.

The population sample size was calculated by assuming an osteoporosis prevalence of $14.7 \%,{ }^{21}$ from which a sample of 374 women was found to be necessary for a precision of 0.035 .

RESULTS

The number of women interviewed was 615 . Of these, 154 did not fulfill the inclusion criteria or were within the exclusion criteria. Thus, the final sample was composed of 461 women. Their mean age ( \pm standard deviation) was $60 \pm 9$ year ( minimum $=45$ and maximum $=90$ years). Their mean weight was $67.6 \pm 12.9 \mathrm{~kg}$ ( minimum $=36$ and maximum $=116 \mathrm{~kg}$ ). Their body mass index (BMI) ranged from 15.8 to $53 \mathrm{~kg} / \mathrm{m}^{2}$ and the mean BMI was $28.8 \pm 5.0 \mathrm{~kg} / \mathrm{m}^{2}$.

Figure 1 presents the distribution of the 461 women who took part in the study, according to their BMI classification. It can be seen that $180(39 \%)$ of them were classified as overweight (BMI between 25 and $\left.29.9 \mathrm{~kg} / \mathrm{m}^{2}\right)$ and only three women $(0.7 \%)$ were underweight $(\mathrm{BMI}<18.5)$.

The Osteorisk classification showed that $61 \%$ of the patients presented low risk, $28.4 \%$ medium risk and $10.6 \%$ high risk of osteoporosis, while ultrasonometry classified
$81.3 \%$ as low risk, $10 \%$ as medium risk and $8.7 \%$ as high risk (Tables 1 and 2).

Considering the ultrasonometry and Osteorisk results together, it was seen that $54.2 \%$ of the patients were classified as low risk, $4.6 \%$ as medium risk and $3.0 \%$ as high risk by both Osteorisk and ultrasonometry (Table 3).

\section{ANALYSIB OF DGTEDRIBK IN RELATION TD AEE, BMI AND YEARS GINCE MENDPAUSE.}

For Osteorisk, statistically significant results were found in relation to analyses of age, BMI and years since menopause (Table 4). With regard to age, the high-risk pa-

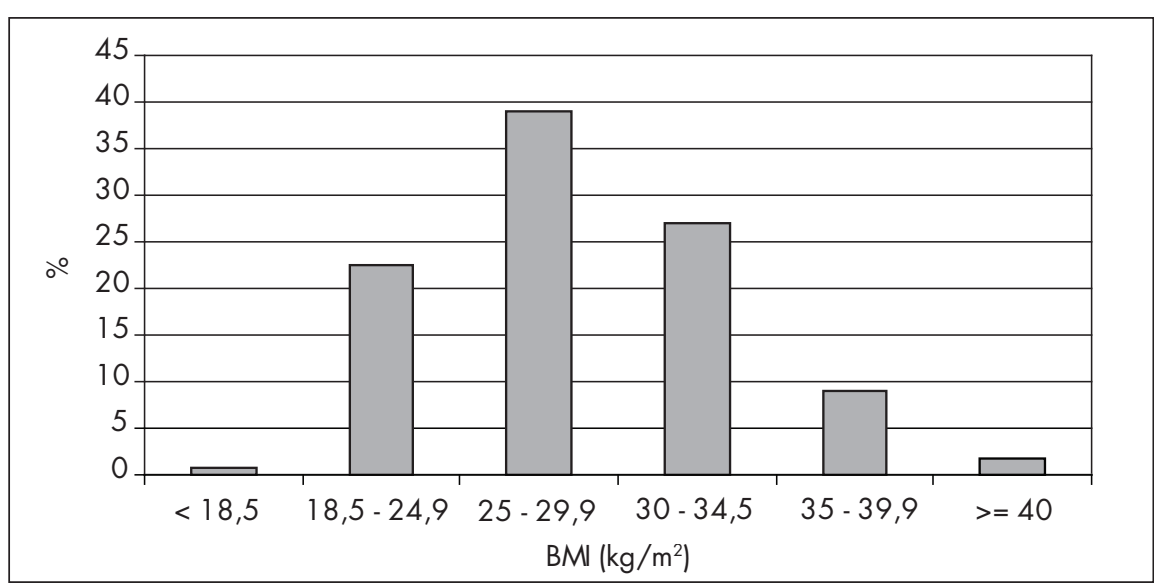

Figure 1. Patient distribution according to body mass index (BMI) classification.

Table 1. Patient distribution according to quantitative ultrasound classification

\begin{tabular}{lc}
\hline Quantitative ultrasound classification & $\mathbf{n}(\%)$ \\
\hline Low risk & $375(81.3 \%)$ \\
Medium risk & $46(10.0 \%)$ \\
High risk & $40(8.7 \%)$ \\
Total & $\mathbf{4 6 1}(100.0 \%)$ \\
\hline
\end{tabular}

Table 2. Patient distribution according to Osteorisk classification

\begin{tabular}{lc}
\hline Osteorisk & $\mathbf{n}(\%)$ \\
\hline Low risk & $281(61 \%)$ \\
Medium risk & $131(28.4 \%)$ \\
High risk & $49(10.6 \%)$ \\
Total & $461(100 \%)$ \\
\hline
\end{tabular}

Table 3. Patient distribution according to results obtained from Osteorisk and quantitative ultrasound on the heel

\begin{tabular}{lcccc}
\hline \multicolumn{4}{c}{ Quantitative ultrasound } \\
\hline Osteorisk & Low risk & Medium risk & High risk & Total (Osteorisk) \\
Low risk & $250(54.2 \%)$ & $20(4.3 \%)$ & $11(2.4 \%)$ & $281(61.0 \%)$ \\
Medium risk & $95(20.6 \%)$ & $21(4.6 \%)$ & $15(3.3 \%)$ & $131(28.4 \%)$ \\
High risk & $30(6.5 \%)$ & $5(1.1 \%)$ & $14(3.0 \%)$ & $49(10.6 \%)$ \\
Total (quantitative ultrasound) & $\mathbf{3 7 5 ( 8 1 . 3 \% )}$ & $\mathbf{4 6}(10.0 \%)$ & $\mathbf{4 0}(\mathbf{8 . 7} \%)$ & $\mathbf{4 6 1}(\mathbf{1 0 0 . 0 \% )}$ \\
\hline
\end{tabular}

Table 4. Age, body mass index and years since menopause (mean \pm standard deviation) according to Osteorisk

\begin{tabular}{lcccc}
\hline & \multicolumn{3}{c}{ Osteorisk } & \multirow{2}{*}{ p-value* $^{*}$} \\
\cline { 2 - 4 } & $\begin{array}{c}\text { Low risk } \\
(\mathbf{n}=\mathbf{2 8 1})\end{array}$ & $\begin{array}{c}\text { Medium risk } \\
(\mathbf{n}=\mathbf{1 3 1 )}\end{array}$ & $\begin{array}{c}\text { High risk } \\
(\mathbf{n}=\mathbf{4 9})\end{array}$ & \\
\hline Age (years) & $56.2 \pm 6.3$ & $62.6 \pm 8.4$ & $74.4 \pm 8.5$ & $<0.001$ \\
Body mass index $\left(\mathrm{kg} / \mathrm{m}^{2}\right)$ & $30.9 \pm 4.7$ & $25.9 \pm 3.4$ & $24.0 \pm 3.3$ & $<0.001$ \\
Years since menopause & $8.4 \pm 7.3$ & $14.1 \pm 9.4$ & $26.1 \pm 9.8$ & $<0.001$ \\
\hline
\end{tabular}

*Analysis of variance (ANOVA) using Brown-Forsythe correction. 
tients presented a mean age that was statistically greater than the ages presented by medium and low-risk patients. The medium-risk patients presented a greater mean age than that of the low-risk patients. For BMI, the high-risk patients presented a BMI that was statistically lower than the BMIs of the medium and lowrisk patients. Regarding the number of years since the menopause, the high-risk patients presented a statistically greater number of years than did the medium and low-risk patients (Table 4).

\section{ANALYBIB OF ULTRABDNDMETRY IN RELATION TO AGE, BMI AND YEARE GINCE MENOPAUEE}

It can be seen from Table 5 that the ultrasonometry showed significant differences with regard to the variables of age ( $p<0.001)$, BMI $(\mathrm{p}=0.006)$ and years since menopause $(\mathrm{p}<0.001)$. Thus, patients with osteoporosis presented on average a statistically greater age than did the patients with osteopenia or a normal examination. The BMI statistically differentiated the normal patients from those with osteopenia and osteoporosis, although it was not capable of differentiating between the patients in the latter two groups. The number of years since menopause was statistically greater among the women with osteoporosis than among those with osteopenia and normal results.

Table 5. Age, body mass index and years since menopause (mean \pm standard deviation) according to quantitative ultrasound

\begin{tabular}{lcccc}
\hline & \multicolumn{3}{c}{ Quantitative ultrasound } & \\
\cline { 2 - 4 } & $\begin{array}{c}\text { Low risk } \\
(\mathbf{n}=\mathbf{3 7 5})\end{array}$ & $\begin{array}{c}\text { Medium risk } \\
(\mathbf{n}=\mathbf{4 6})\end{array}$ & $\begin{array}{c}\text { High risk } \\
(\mathbf{n}=\mathbf{4 0 )}\end{array}$ & p-value* \\
\hline Age (years) & $58.7 \pm 8.3$ & $61.4 \pm 8.8$ & $70.6 \pm 10.2$ & $<0.001$ \\
Body mass index $\left(\mathrm{kg} / \mathrm{m}^{2}\right)$ & $29.1 \pm 4.9$ & $27.3 \pm 4.5$ & $26.9 \pm 6.0$ & 0.006 \\
Years since menopause & $10.5 \pm 9.1$ & $15.2 \pm 10.1$ & $21.4 \pm 11.6$ & $<0.001$ \\
\hline
\end{tabular}

*Analysis of variance (ANOVA) using Brown-Forsythe correction.

Table 6. Correlation between Osteorisk and qualitative ultrasound, considering low risk versus medium and high risk

\begin{tabular}{lccc}
\hline \multirow{2}{*}{ Osteorisk } & \multicolumn{2}{c}{ Quantitative ultrasound } & \multirow{2}{*}{ Total } \\
\cline { 2 - 3 } & Medium and high risk & Low risk & \\
\hline Medium and high risk & $55(11.9 \%)$ & $125(27.1 \%)$ & $180(39.0 \%)$ \\
Low risk & $31(6.7 \%)$ & $250(54.2 \%)$ & $281(61.0 \%)$ \\
Total & $\mathbf{8 6}(\mathbf{1 8 . 7 \% )}$ & $\mathbf{3 7 5}(\mathbf{8 1 . 3} \%)$ & $\mathbf{4 6 1}(\mathbf{1 0 0 . 0 \% )}$ \\
\hline
\end{tabular}

Table 7. Sensitivity, specificity, positive predictive value and negative predictive value for Osteorisk

\begin{tabular}{lcc}
\hline & Value & $95 \%$ confidence interval \\
\hline Sensitivity & $64 \%$ & {$[53.4 \% ; 73.3 \%]$} \\
Specificity & $66.7 \%$ & {$[61.7 \% ; 71.2 \%]$} \\
Negative predictive value & $89.0 \%$ & {$[84.8 \% ; 92.1 \%]$} \\
Positive predictive value & $30.6 \%$ & {$[24.3 \% ; 37.6 \%]$} \\
\hline
\end{tabular}

ever, indiscriminate screening of all patients by this method is impossible in Brazil because of its high cost and low availability, particularly for the social classes with lower income.

Today, there are methods like ultrasonometry on the heel that can be used for evaluating the risk of fracture, both at peripheral and at central sites, with performance resembling measurements of central BMD. The exception to this is calculations of the risk of hip fractures, which are more precise with bone densitometry on the hip. The BMD of the peripheral skeleton, including the distal radius, phalanx and heel, correlates reasonably well with the density of the axial skeleton (hip and spinal column, and the costs of obtaining these data are more accessible. ${ }^{2,8,23,24}$

In this light, we undertook a comparison between Osteorisk and ultrasonometry on the heel, among women living in São Bernardo do Campo, to evaluate the effectiveness of Osteorisk as a screening method for identifying the patients who were more susceptible to osteoporosis. We evaluated our population in relation to age, $\mathrm{BMI}$ and number of years since the menopause. In both the Osteorisk and the ultrasonometry analyses, all these variables presented statistical significance.

BMI has an inverse relationship with osteoporosis, and this was confirmed in our sample, both for Osteorisk and for ultrasonometry. In both analyses, we observed that the low-risk patients had BMI that was statistically significantly greater than among those at high risk.

Age has a direct relationship with osteoporosis, and this was confirmed in our study: low-risk patients as assessed by Osteorisk presented a mean age of 18.2 years lower than did the high-risk patients; and for ultrasonometry on the heel, 11.9 years. In relation to the number of years since the menopause too, our data were concordant with the literature, establishing a directly proportional relationship between the number of years since the menopause and osteoporosis. Low-risk patients as assessed by Osteorisk presented 17.7 years less since the menopause than did those at high risk, and for ultrasonometry this value was 10.9 years.

If Osteorisk were to be proven satisfactory, it could be utilized as an alternative to screening by means of bone densitometry. According to Sen et al., ${ }^{4}$ Osteorisk presented sensitivity greater than $90 \%$ for identifying patients who were at risk of osteoporosis. We applied Osteorisk to the population studied and compared it with the results from quantitative ultrasonometry on the heel, while 
maintaining the definitions of the World Health Organization. ${ }^{25}$ for osteoporosis, osteopenia and normal bone mass. These were established by measuring bone mass using bone densitometry and comparing this with a young population (T-score). ${ }^{2,19}$

One important matter that is still controversial is the precision of using peripheral measurements for evaluating bone mass, in comparison with the central measurements that are used by WHO., ${ }^{214,22,23}$ It has been observed that, in using peripheral measurements (among which ultrasonometry on the heel), there is a lower percentage of osteoporosis identification than when BMD measurements on the axial skeleton are used. ${ }^{2,6,22,23}$ There are references in the literature that defend and utilize a higher cutoff point of -1.8 standard deviations for identifying the risk of osteoporosis, when the BMD is evaluated by ultrasonometry. Through this, the percentage of osteoporosis identification would be very similar to what is found by conventional densitometry. ${ }^{2,6,22,23}$ On the basis of this analysis, we chose in our study to take the women who were at high risk of osteoporosis to be those whose ultrasonometry values were lower than a T-score of -2.0 , medium risk to be between -1.5 and -1.99 and low risk to be a T-score higher than -1.5 . From this classification, ultrasonometry detected that $8.7 \%$ of the women were at high risk of osteoporosis. It should be emphasized that this value was close to the prevalence of osteoporosis identified in the literature by using bone densitometry, which ranges from 7 to $8 \% .^{2,22,23}$

We considered it to be of interest to evaluate the validation of the Osteorisk method by identifying the risk of osteoporosis in comparison with ultrasonometry. The values obtained demonstrated sensitivity of $64 \%$ and specificity of $66.7 \%$ for identifying patients at medium and high risk of osteoporosis. The positive predictive value, which indicates the likelihood that medium and high-risk patients as assessed by Osteorisk are really medium and high-risk using ultrasonometry, was $30.6 \%$. The negative predictive value, which indicates the likelihood that low-risk patients as assessed by Osteorisk are really low-risk using ultrasonometry, was $89 \%$.

Assessing the results, we noted that Osteorisk presented a false negative rate of $36 \%$, in comparison with ultrasonometry. This represents a limitation to the use of this clinical tool, because such patients would fail to be diagnosed, since they would be erroneously considered to be at low risk. It would be of interest to have greater sensitivity in order to use Osteorisk with assurance. Nonetheless, it must not be neglected that Osteorisk also presented a high negative predictive value and would correctly select $64 \%$ of the patients who were identified by means of dual X-ray absorptiometry (DXA).

We are aware that our conclusions leave room for criticism. In our defense, we must first cite the fact that our study population included individuals of black race and thus differed from the population evaluated by the authors of the Osteorisk method, which did not include such individuals. ${ }^{4}$ It is known that ethnic origin has a relationship with osteoporosis, which is more prevalent among Caucasians and less so among Africans. ${ }^{4,8,14} \mathrm{We}$ can also cite the fact that $77 \%$ of the women in our population had a BMI of more than $25 \mathrm{~kg} / \mathrm{m}^{2}$. This is highly relevant for the sample, since one of the variables for Osteorisk is precisely the weight.

We are also aware that ultrasonometry on the heel is not a gold standard for evaluating BMD and that its real effectiveness in identifying osteoporosis is not totally defined. , $8,14,16,22,23$ Studies have highlighted its usefulness for identifying patients who are at risk of fractures, but even this idea is not fully grounded. In the national osteoporosis risk assessment (NORA) study, peripheral measurements on patients who presented fractures after 12 months of follow-up showed that only $18 \%$ of these patients would have received treatment for fractures if the cutoff criterion had been T-score $\leq 2.5$, and 22.6\% using the criterion of the National Osteoporosis Foundation (NOF). ${ }^{8}$ Perhaps alteration of the evaluation cutoff point for peripheral measurements, as already described, would be a viable solution that would increase the effectiveness of these measurements for identifying osteoporosis and risks of fractures. Studies in Latin America, and especially in Brazil, comparing Osteorisk and ultrasonometry on the heel with bone densitometry would be of great importance for validating these diagnostic methods.

\section{CONCLUSIRN}

Our study allows the conclusion that Osteorisk is a valid tool for screening for women who are at low risk of osteoporosis, thereby making it possible not to have to perform bone densitometry on this group. 
1. Lin JT, Lane JM. Osteoporosis: a review. Clin Orthop Relat Res. 2004;(425):126-34.

2. Vu TT, Nguyen CK, Nguyen TL, et al. Determining the prevalence of osteoporosis and related factors using quantitative ultrasound in Vietnamese adult women. Am J Epidemiol. 2005;161(9):824-30.

3. Fernandes CE, Wehba S, Melo NR. Osteoporose pós-menopáusica. In: Oliveira HC, Lemgruber I, editors. Tratado de Ginecologia Febrasgo. Rio de Janeiro: Revinter; 2001. p. 679-93.

4. Sen SS, Rives VP, Messina OD, et al. A risk assessment tool (OsteoRisk) for identifying Latin American women with osteoporosis. J Gen Intern Med. 2005;20(3):245-50.

5. Cadarette SM, Jaglal SB, Kreiger N, McIsaac WJ, Darlington GA, Tu JV. Development and validation of the Osteoporosis Risk Assessment Instrument to facilitate selection of women for bone densitometry. CMAJ. 2000;162(9):1289-94.

6. Miller PD, Barlas S, Brenneman SK, et al. An approach to identifying osteopenic women at increased short-term risk of fracture. Arch Intern Med. 2004;164(10):1113-20.

7. Lacroix AZ, Buist DS, Brenneman SK, Abbott TA 3rd. Evaluation of three population-based strategies for fracture prevention: results of the osteoporosis population-based risk assessment (OPRA) trial. Med Care. 2005;43(3):293-302.

8. Siris ES, Miller PD, Barrett-Connor E, et al. Identification and fracture outcomes of undiagnosed low bone mineral density in postmenopausal women: results from the National Osteoporosis Risk Assessment. JAMA. 2001;286(22):2815-22.

9. Siris ES, Chen YT, Abbott TA, et al. Bone mineral density thresholds for pharmacological intervention to prevent fractures. Arch Intern Med. 2004;164(10):1108-12.

10. Buist DS, LaCroix AZ, Manfredonia D, Abbott T. Identifying postmenopausal women at high risk of fracture in populations: a comparison of three strategies. J Am Geriatr Soc. 2002;50(6):1031-8
11. Wehren LE, Siris ES. Beyond bone mineral density: can existing clinical risk assessment instruments identify women at increased risk of osteoporosis? J Intern Med. 2004;256(5):375-80.

12. Richy F, Deceulaer F, Ethgen $\mathrm{O}$, Bruyère $\mathrm{O}$, Reginster JY Development and validation of the ORACLE score to predict risk of osteoporosis. Mayo Clin Proc. 2004;79(11):1402-8.

13. Salaffi F, Silveri F, Stancati A, Grassi W. Development and validation of the osteoporosis prescreening risk assessment (OPERA) tool to facilitate identification of women likely to have low bone density. Clin Rheumatol. 2005;24(3):203-11.

14. Rothenberg RJ, Boyd JL, Holcomb JP. Quantitative ultrasound of the calcaneus as a screening tool to detect osteoporosis: different reference ranges for caucasian women, african-american women, and caucasian men. J Clin Densitom. 2004;7(1):101-10.

15. Blake GM, Fogelman I. Clinical use of instruments that measure peripheral bone mass. Parathyroids and bone and mineral metabolism. Curr Opin Endocrinol Diabetes Obes. 2002;9(6):502-11. Available from: http://www.co-endocrinology.com/pt/re/coendo/abstract.00060793-200212000-00010. htm;jsessionid=H0GK9n2dJG5nznPpgK4J31tTdqQRxlNnn KZ9FZCzHvw2bySKCq4j!!1821113646!181 195629!8091!-1. Accessed in 2007 (Nov 9).

16. Geusens P, Hochberg MC, van der Voort DJ, et al. Performance of risk indices for identifying low bone density in postmenopausal women. Mayo Clinic Proc. 2002;77(7):629-37.

17. Koh LK, Sendrine WB, Torralba TP, et al. A simple tool to identify asian women at increased risk of osteoporosis. Osteoporos Int. 2001;12(8):699-705

18. Brasil. Ministério do Planejamento, Orçamento e Gestão Instituto Brasileiro de Geografia e Estatística. População residente, por sexo e populaçáo cedida, segundo o código e o município - São Paulo. Available from: http://wwwl.ibge. gov.br/home/estatistica/populacao/contagem/spcont $97 . s h t m$. Accessed in 2008 (Jan 7)
19. Cheng S, Fan B, Wang L, et al. Factors affecting broadband ultrasound attenuation results of the calcaneus using a gelcoupled quantitative ultrasound scanning system. Osteoporos Int. 1999;10(6):495-504.

20. Altman DG. Comparing Groups - Continous and Categorical Data In: Altman DG, ed. Practical statistics for medical research. London: Chapman \& Hall/CRC; 1991. p. 179-223.

21. Costa-Paiva L, Horovitz AP, Santos AO, Fonsechi-Carvasan GA, Pinto-Neto AM. Prevalência de osteoporose em mulheres na pós-menopausa e associaçăo com fatores clínicos e reprodutivos. \{Prevalence of osteoporosis in postmenopausal women and association with clinical and reproductive factors]. Rev Bras Ginecol Obstet. 2003;25(7):507-12.

22. Kern LM, Powe NR, Levine MA, et al. Association between screening for osteoporosis and the incidence of hip fracture. Ann Intern Med. 2005;142(3):173-81.

23. Frost ML, Blake GM, Fogelman I. Can the WHO criteria for diagnosing osteoporosis be applied to calcaneal quantitative ultrasound? Osteoporos Int. 2000;11(4):321-30.

24. Frost ML, Blake GM, Fogelman I. Contact quantitative ultrasound: an evaluation of precision, fracture discrimination, age-related bone loss and applicability of the WHO criteria. Osteoporos Int. 1999;10(6):441-9.

25. Assessment of fracture risk and its application to screening fo postmenopausal osteoporosis. Report of a WHO Study Group. World Health Organ Tech Rep Ser. 1994;843:1-129.

\section{Sources of funding: None}

Conflicts of interest: Assistance was received in the form of the Sonost 2000 ultrasonometry equipment, which was supplied by the Lilly Laboratory

Date of first submission: February 27, 2007

Last received: January 7, 2008

Accepted: January 7, 2008

\section{AUTHOR INFORMATION}

Marcelo Luis Steiner, MD. Postgraduate student in Health Sciences, Faculdade de Medicina do ABC, São Bernardo do Campo, São Paulo, Brazil.

César Eduardo Fernandes, MD, MSc, PhD. Head of the Endocrine Gynecology and Climacteric Sector, Department of Gynecology and Obstetrics, Faculdade de Medicina do $A B C$, São Bernardo do Campo, São Paulo, Brazil.

Rodolfo Strufaldi, MD. Assistant lecturer, Department of Gy necology and Obstetrics, Faculdade de Medicina do ABC, São Bernardo do Campo, São Paulo, Brazil.

Lucia Helena de Azevedo, MD, MSc, PhD. Attending physician, Endocrine Gynecology and Climacteric Sector Department of Gynecology and Obstetrics, da Faculdade de Medicina do ABC.

Cristina Stephan, MD, MSc. Attending physician, Endocrine Gynecology and Climacteric Sector, Department of Gynecology and Obstetrics, Faculdade de Medicina do ABC, São Bernardo do Campo, São Paulo, Brazil.

Luciano Melo Pompei, MD, MSc, PhD. Attending physician, Endocrine Gynecology and Climacteric Sector, Department of Gynecology and Obstetrics, Faculdade de Medicina do $A B C$, São Bernardo do Campo, São Paulo, Brazil.

Sérgio Peixoto, MD, MSc, PhD. Titular professor, Department of Gynecology and Obstetrics, Faculdade Medicina do ABC, São Bernardo do Campo, São Paulo, Brazil.

\section{Address for correspondence:}

Marcelo Luis Steiner

Rua Dr. Miranda de Azevedo, 1.059

São Paulo (SP) - Brasil - CEP 05027-000

Tel. (+55 11) 3871-2058 - Fax. (+55 11) 3825

9315 - Cel. (+55 11) 9295-6348

E-mail: masteiner@ig.com.br

Copyright (c) 2008, Associação Paulista de Medicina
RESUMロ

Estudo da acurácia do "Osterisk": uma nova ferramenta clínica para o rastreamento da osteoporose em mulheres acima de 50 anos

CONTEXTO E OBJETIVO: Osteoporose é a principal causa de redução de qualidade de vida, morbidade e mortalidade entre as mulheres no climatério, com aumento na incidência conforme o envelhecimento da população. Ferramentas clínicas como Ostorisk fornecem uma alternativa de acesso fácil e de baixo custo que ajudam o clínico a melhorar a eficácia da solicitação da densitometria óssea, exame padrão ouro, porém caro para o diagnóstico de osteoporose. O objetivo deste artigo foi estudar a acurácia do Ostorisk tendo a ultrassonometria de calcâneo como método de avaliação da densidade mineral óssea.

TIPO DE ESTUDO E LOCAL: Estudo transversal, na Faculdade de Medicina do ABC.

MÉTODO: Um questionário estruturado foi aplicado em 615 mulheres menopausadas, com medidas antropométricas, cálculo do Osteorisk e realização de ultrassonometria quantitativa do calcâneo com o aparelho Sonost 2000

RESULTADOS: 461 mulheres foram incluídas, com uma idade média de $60 \pm 9$ anos, peso de $67,6 \pm 12,9 \mathrm{~kg}$ e índice de massa corpórea (IMC) $28,8 \pm 5.0 \mathrm{~kg} / \mathrm{m}^{2}$. A classificação do Osteorisk para o grupo estudado foi: $61,0 \%$ baixo risco, $28,4 \%$ médio risco, e 10,6\% alto risco. A ultrassonometria de calcâneo mostrou $81,3 \%$ baixo risco, $10,0 \%$ médio risco e $8,7 \%$ alto risco para osteoporose. Os resultados estatisticamente significantes foram observados $(p<0,001)$ quando o Osteorisk foi correlacionado com idade, anos de menopausa e índice de massa corpórea (IMC). Correlacionando essas mesmas variedades com a ultrasonometria, resultados estatisticamente significantes foram observados para idade ( $<<0,001)$, anos de menopausa $(p<0,001)$ e IMC ( $p<0,006)$. A sensibilidade, especificidade, o valor preditivo negativo e o valor preditivo positivo para o Osteorisk foram $64 \%, 6,7 \%, 89 \%$ e 30,6\%, respectivamente.

CONCLUSÃO: Osteorisk é uma ferramenta válida para o rastreamento de mulheres com baixo risco para desenvolver osteoporose, permitindo que estas não precisem ser submetidas à densitometria óssea.

PALAVRAS-CHAVE: Osteoporose. Densidade mineral óssea. Peneiramento. Ultra-sonografia. Fatores de risco. 